\title{
Morpho-physiological integrators, transcriptome and coexpression network analyses signify the novel molecular signatures associated with axillary bud in chrysanthemum
}

\author{
Sagheer Ahmad', Cunquan Yuan', Qingqing Yang ${ }^{1}$, Yujie Yang ${ }^{1}$, Tangren Cheng ${ }^{1}$, Jia Wang ${ }^{1}$, Huitang Pan ${ }^{1}$ and \\ Qixiang Zhang ${ }^{1,2^{*}}$
}

\begin{abstract}
Background: Axillary bud is an important agronomic and economic trait in cut chrysanthemum. Bud outgrowth is an intricate process controlled by complex molecular regulatory networks, physio-chemical integrators and environmental stimuli. Temperature is one of the key regulators of bud's fate. However, little is known about the temperature-mediated control of axillary bud at molecular levels in chrysanthemum. A comprehensive study was designed to study the bud outgrowth at normal and elevated temperature in cut chrysanthemum. Leaf morphology, histology, physiological parameters were studied to correlate the leaf activity with bud morphology, sucrose and hormonal regulation and the molecular controllers.
\end{abstract}

Results: Temperature caused differential bud outgrowth along bud positions. Photosynthetic leaf area, physiological indicators and sucrose utilization were changed considerable due to high temperature. Comparative transcriptome analysis identified a significant proportion of bud position-specific genes.Weighted Gene Coexpression Network Analysis (WGCNA) showed that axillary bud control can be delineated by modules of coexpressed genes; especially, MEtan3, MEgreen2 and MEantiquewhite presented group of genes specific to bud length. A comparative analysis between different bud positions in two temperatures revealed the morphophysiological traits associated with specific modules. Moreover, the transcriptional regulatory networks were configured to identify key determinants of bud outgrowth. Cell division, organogenesis, accumulation of storage compounds and metabolic changes were prominent during the bud emergence.

(Continued on next page)

\footnotetext{
* Correspondence: zqx@bjfu.edu.cn

'Beijing Key Laboratory of Ornamental Plants Germplasm Innovation \&

Molecular Breeding, National Engineering Research Center for Floriculture, Beijing Laboratory of Urban and Rural Ecological Environment, Key Laboratory of Genetics and Breeding in Forest Trees and Ornamental Plants of Ministry of Education, School of Landscape Architecture, Beijing Forestry University, Beijing 100083, China

${ }^{2}$ Beijing Advanced Innovation Center for Tree Breeding by Molecular Design,

Beijing Forestry University, Beijing 100083, China
}

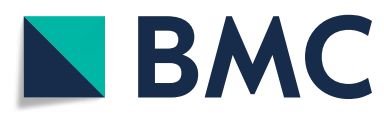

(c) The Author(s). 2020 Open Access This article is licensed under a Creative Commons Attribution 4.0 International License, which permits use, sharing, adaptation, distribution and reproduction in any medium or format, as long as you give appropriate credit to the original author(s) and the source, provide a link to the Creative Commons licence, and indicate if changes were made. The images or other third party material in this article are included in the article's Creative Commons licence, unless indicated otherwise in a credit line to the material. If material is not included in the article's Creative Commons licence and your intended use is not permitted by statutory regulation or exceeds the permitted use, you will need to obtain permission directly from the copyright holder. To view a copy of this licence, visit http://creativecommons.org/licenses/by/4.0/ The Creative Commons Public Domain Dedication waiver (http://creativecommons.org/publicdomain/zero/1.0/) applies to the data made available in this article, unless otherwise stated in a credit line to the data. 
(Continued from previous page)

Conclusions: RNA-seq data coupled with morpho-physiological integrators from three bud positions at two temperature regimes brings a robust source to understand bud outgrowth status influenced by high temperature in cut chrysanthemum. Our results provide helpful information for elucidating the regulatory mechanism of temperature on axillary bud growth in chrysanthemum.

Keywords: High temperature, Axillary bud, WGCNA, Chrysanthemum,

\section{Background}

Branches, besides being the architectural determinants, provide plants with plenty of shapes and ornamental values. Axillary bud is one of the most important agronomic traits related to cut floral beauty; especially in chrysanthemum where excessive outgrowth of axillary branches is a major drawback in market success of cut flowers. Since antiquity, strides have been directed towards the temperature control, manual disbudding and the molecular regulation of axillary growth. However, due to limited access to the complex genomic structure of this crop, the bud control remained a mystery for the researchers. Recently, the whole genome sequencing [1] have facilitated the tracing of axillary bud regulation at molecular levels. With this breakthrough, a comprehensive assessment of molecular regulatory mechanism of bud outgrowth controlled by temperature can point out important thermal inhibitors of axillary bud.

High-definition transcriptomic investigations in different plants have provided valuable insights into the molecular pathways and networks, and their interactions with different aspects of bud outgrowth [2-7]. The molecular mechanism behind bud outgrowth has been demonstrated to some depth in some plants [2, 8]. Carbohydrate distribution, photoassimilate supply and the accumulation rate of storage compounds during bud initiation are important regulators of bud outgrowth [9-11]. Moreover, epigenetic imprinting and hormonal signal transduction have also been considered as pivotal regulators of bud kinetics [1217]. Along with these regulators, temperature is also considered pivotal when studying bud opening and outgrowth.

However, after the report of Faust and Heins [18], stating that chrysanthemum (Powerhouse) produces little axillary shoots at $35^{\circ} \mathrm{C}$; no further progress could be made in chrysanthemum. Temperature elevation beyond a certain level can cause sterile spikelet [19]; as suggested to be due to high temperature [20-23]. The recent researches have shown many spikelet-related DEGs sensitive to heat stress [19] and a high temperature exposure of $39^{\circ} \mathrm{C}$ suppressed the spikelet fertility [23]. Gene expression profiling of rice panicles growing at $40{ }^{\circ} \mathrm{C}$ identified DEGs involving mainly in transport, transcriptional regulation, stress response and cellular homeostasis [24]. Moreover, the pattern of gene expression due to heat stress and the regulation model based on ROS (reactive oxygen species) along with transcriptome implied the importance of ROS balance in panicle growth [24]. According to a report on rice genome, one half of the genes (50.4\%) expressed at $25^{\circ} \mathrm{C}$ and another half $(50.2 \%)$ expressed at $30^{\circ} \mathrm{C}$; moreover, temperature stimulated many transcription factor families, including WRKY, bZIP, and MYB [25]. Thus far, nothing is documented on the transcriptional mechanism of axillary bud outgrowth in response to high temperature in cut chrysanthemum.

Temperature extremes can cause water stress, thereby triggering the reactive oxygen species (ROS) [26-28]. Excessive accumulation of ROS can cause oxidative harm to lipids leading to the production of MDA (malondialdehyde), an indicator of oxidative stress level in plants [29]. Plants use antioxidant defense system to cope with the accumulation of ROS. This system uses water-soluble reducing agents (e.g., glutathione and ascorbate), lipid-soluble antioxidants (e.g., carotene and $\alpha$ tocopherol) and enzymes like SOD (superoxide dismutase) $[27,30]$. Thus, deciphering the accumulation of SOD and MDA can expose the damages caused by water stress and/or temperature stress. SOD triggers the catalysis of superoxide radical to $\mathrm{H}_{2} \mathrm{O}_{2}$ and $\mathrm{O}_{2}$ through a spontaneous and extremely fast reaction in order to defend the plant cells from the products of superoxide radical reaction. The potentially toxic compound is reduced to water through the action of enzymes, such as catalase (CAT) and peroxidase (POD) [31, 32]. CAT converts hydrogen per oxide $\left(\mathrm{H}_{2} \mathrm{O}_{2}\right)$ to $\mathrm{H}_{2} \mathrm{O}$ and $\mathrm{O}_{2}$.

Chrysanthemum is the second most important floriculture crop in worldwide floriculture trade [33, 34], sharing $30 \%$ of the total cut flower production in the world. Axillary branching is a vital end-user quality attribute of cut chrysanthemum. Diminished axillary bud growth is highly desirable to provide high market price for cut flowers. The accessibility to its genomic sequences and the transcriptome [1] along with RNASequencing can do a great deal to reveal genetic regulation of bud initiation and outgrowth in cut chrysanthemum. A few efforts have been made to understand the transcriptomic basis of bud development [2, 3, 6]. However, no such strides have been made to find the temperature-mediated molecular mechanism behind bud initiation and outgrowth in chrysanthemum. 
To the best of our knowledge, a comparative transcriptome analysis of bud outgrowth, at different positions, at different temperatures has not yet been performed in cut chrysanthemum. Here, we applied RNA-Seq technology to analyze axillary bud transcriptome at two different temperatures (i.e., $25^{\circ} \mathrm{C}$ and $35^{\circ} \mathrm{C}$ ). The data were dissected to ascertain transcriptome dynamics and the transcriptional regulatory networks linked with bud outgrowth. The coexpressed gene modules were identified for each bud position under contrasting temperatures. Moreover, spacial control of photoassimilates and the chemical homeostasis by leaves were also studied as indirect controlling mechanism for bud regulation. Thus, this study gives valuable insights into the molecular regulatory mechanism and the pivotal factors governing axillary bud outgrowth.

\section{Results}

High temperature causes morpho-physiological changes in plants [35] and removing leaves retards bud outgrowth, showing the importance of leaf-derived physio-metabolic factors in axillary bud control [36]. Therefore, connecting leaf dynamics with bud outgrowth can be an effective tool to understand the leaf-mediated influence of temperature.

\section{Bud positions express differently for high and normal temperature}

At an extended plant height $(35-40 \mathrm{~cm})$ the plant shows maximum bearing of axillary buds at all positions
(Supplementary Fig. 1). At this stage, high density of axillary growth was seen in normal temperature regime as compared to high temperature. Top buds retained the growth potential at both the temperatures. However, high temperature almost completely checked the outgrowth of top axillary buds (TAB). More axillary growth was seen at lower axillary positions at $25^{\circ} \mathrm{C}$, whereas it was restricted in high temperature regime, suggesting that different bud positions respond differently against temperature changes.

\section{Temperature indirectly affects bud kinetics via leaf}

Among the leaf morphological indices, leaf area (Fig. 1o), wet to dry mass ratio (Fig. 1q) and stomatal density (Fig. 1p) were observed in 11 days post-transplantation in contrasting temperature regimes. Leaf area was marginally high in normal temperature plants as compared to high temperature. High wet to dry mass ratio was seen in high temperature plants, suggesting more accumulation of photoassimilates in the leaf. However, the stomatal density was significantly high in top bud leaves $\left(50.33 \mathrm{~mm}^{-2}, p<0.01\right)$ in $35^{\circ} \mathrm{C}$ leaves as compared to $24^{\circ} \mathrm{C}$ where only 10.33 stomata were found in $1 \mathrm{~mm}^{-2}$ surface area.

More photosynthesis was observed in $25^{\circ} \mathrm{C}$ plants as compared to $35^{\circ} \mathrm{C}$ (Fig. 1a). Same was the case with transpiration (Fig. 1d) where normal temperature caused more gas exchange. In the case of water conductance

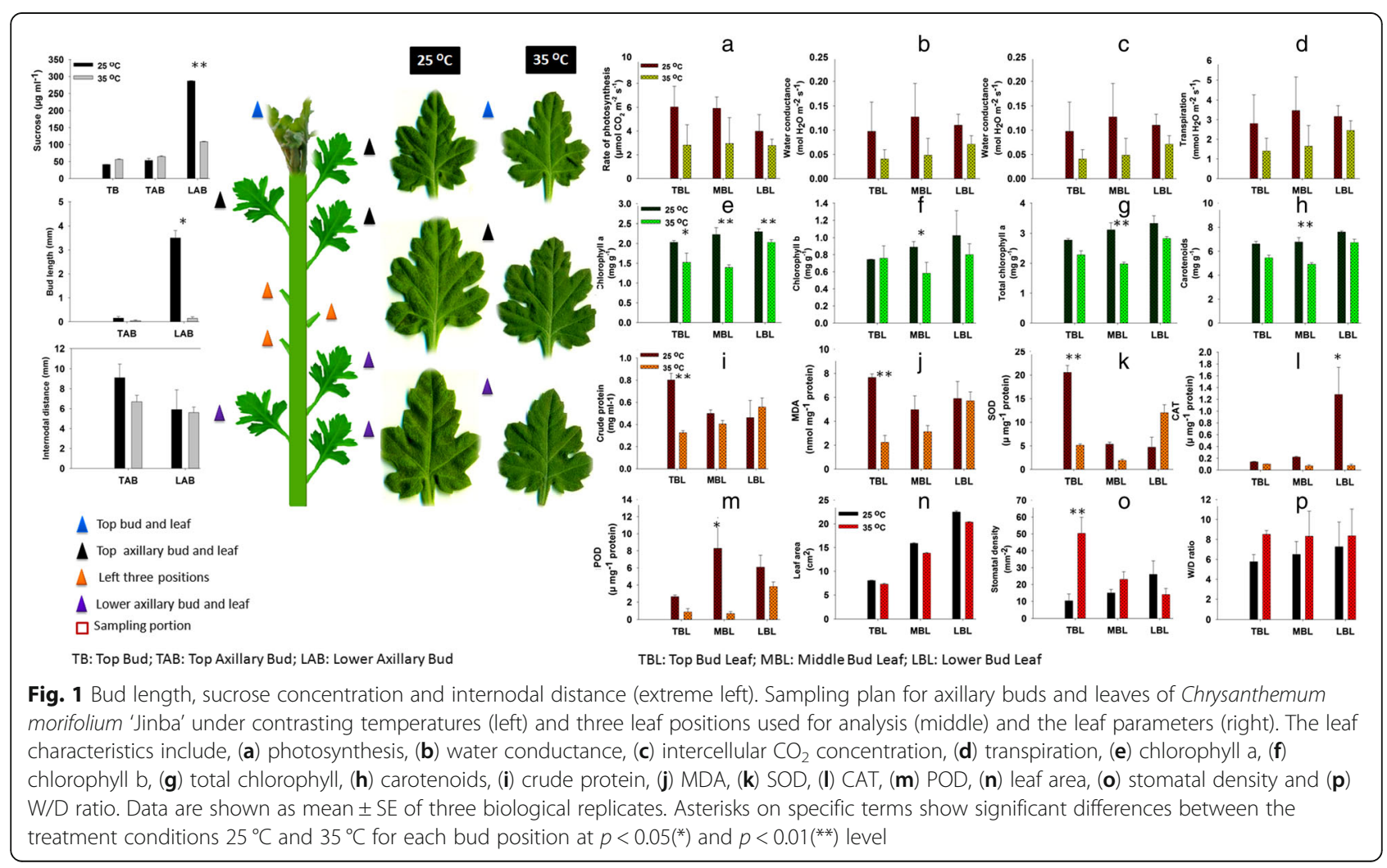


(Fig. 1b), considerable difference was observed at different temperatures as compared to intercellular $\mathrm{CO}_{2}$ concentration (Fig. 1c). Significant changes occurred in chlorophyll contents (Fig. 1e-g) at different temperatures, suggesting positive correlation between photosynthetic pigments and normal temperature. Carotenoids were also observed to be more fluctuating at upper bud leaves due to temperature change (Fig. 1h).

\section{Physiological responses of leaf against temperature} A significant difference $(p<0.01)$ was observed in the top bud leaves (TBL) in crude protein concentration (Fig. 1i). $25^{\circ} \mathrm{C}$ leaves showed significant high MDA content in top bud leaves (Fig. 1j) whereas negligible differences were seen at other bud positions. In case of SOD concentration (Fig. 1k), top leaves showed high concentration in normal temperature and lower bud leaves (LBL) showed high concentration in high temperature. However, the difference was more significant in TBL as compared to LBL. For POD (Fig. 1m), the maximum concentration was shown by TBL in normal temperature than high temperature. However, the TBL and LBL did not show significant differences, except that the POD concentration was little high in normal temperature leaves at both leaf positions. The catalase activity was significant at LBL and CAT concentration was the maximum at $25^{\circ} \mathrm{C}$ than $35^{\circ} \mathrm{C}$. However, at other leaf positions, there was no considerable difference between the leaves at contrasting temperatures (Fig. 11).

\section{Ultra-structural leaf and bud attributes as influenced by temperature variation}

Paraffin sectioning buds showed that high temperature prohibited the bud outgrowth to some extent in all bud positions (Fig. 2a, b). Top buds showed a little restricted growth in high temperature as compared to normal temperature (Fig. 2; A1, B1). However, the marked difference was noted at top axillary buds where bud outgrowth was completely checked by high temperature at the 11th day of growth in contrasting temperatures (Fig. 2, B2). In lower axillary buds, the outgrowth was more at normal temperature (Fig. 2, A3) as compared to high temperature (Fig. 2, B3).

Considering the microscopic examination of leaves (Fig. 2c, d), the leaf mesophyll cells were more arranged and shaped in normal temperature leaves (Fig. 2; C1-C3) as compared to high temperature (Fig. 2; D1-D3), where a mild disruption was seen in the cortex. However, the influence was more prominent in top axillary leaves (Fig. 2; C1, D1), whereby high temperature caused more disrupted growth (Fig. 2, D1) than that of normal temperature (Fig. 2, C1). While observing the stomatal density, the outer surface was also seen via nail polish (Fig. 2e, f). Cell surfaces were presenting some sort of variations against normal (Fig. 2; E1-E3) and high (Fig. 2;
F1-F3) temperature for TBL (E1, F1), MBL (E2-F2) and LBL (E3-F3). Figure 3(g-h) shows the transmission electron micrographs of top axillary leaves for understanding the chloroplast distribution within the cell as influenced by temperature variations.

Temperature causes differential bud outgrowth and sugar distribution along bud positions

Significant difference $(p<0.01)$ of sucrose accumulation was noted at lower axillary buds in normal temperature as compared to high temperature (Fig. 1). However, the difference was not significant at top buds and top axillary buds at both the temperatures except that the sucrose levels were slightly high in high temperature. Significant effect of temperature can be seen in bud length at both temperature regimes, whereby high temperature suppressed the bud outgrowth (Fig. 1). Internodal distance was higher in normal temperature plants as compared to high temperature.

\section{Transcriptome analysis of buds at different positions}

The transcriptome analysis of buds from different positions can give important system-level insights into the molecular regulatory mechanism behind bud initiation and outgrowth. A total of 13 billion high-quality reads (average $\sim 65$ million reads from each sample) were generated for all bud samples and mapped to chrysanthemum genome (v2.0) using TopHat. The mapped reads were processed via cuffdiff to generate normalized expression as FPKM for each transcript. The number of expressed genes varied from 60 to $70 \%$ in different tissues. About $10-15 \%$ of genes showed high expression (FPKM 210 ) (Supplementary Table 1). Overall, these analyses exhibited enough coverage of transcriptome during bud outgrowth in chrysanthemum.

\section{Transcriptomic comparison revealed dynamic relationships among bud stages}

To know the transcriptomic differences in bud outgrowth at two different temperatures, we performed principal component analysis (PCA) and hierarchical clustering based on spearman correlation coefficient analysis of average FPKM values of all the genes expressed in at least one of the 3 tissue samples (Supplementary Fig. 2).

The tissues exhibiting high correlation are supposed to have similarity in transcriptomes and activities. These analyses pointed out higher correlation among similar bud developmental stages between two temperature regimes. It can be seen that bud transcriptomes in $35^{\circ} \mathrm{C}$ were clustering differently as compared to $25^{\circ} \mathrm{C}$ (Supplementary Fig. $2 \mathrm{a}$ ). $35^{\circ} \mathrm{C} \mathrm{TB}$ and $\mathrm{LAB}$ were clustering more close than any of the other tissues and these two were closely placed with $25^{\circ} \mathrm{C} \mathrm{TB}$, suggesting some point of coordination between the two temperature regimes (Supplementary Fig. 2b). 


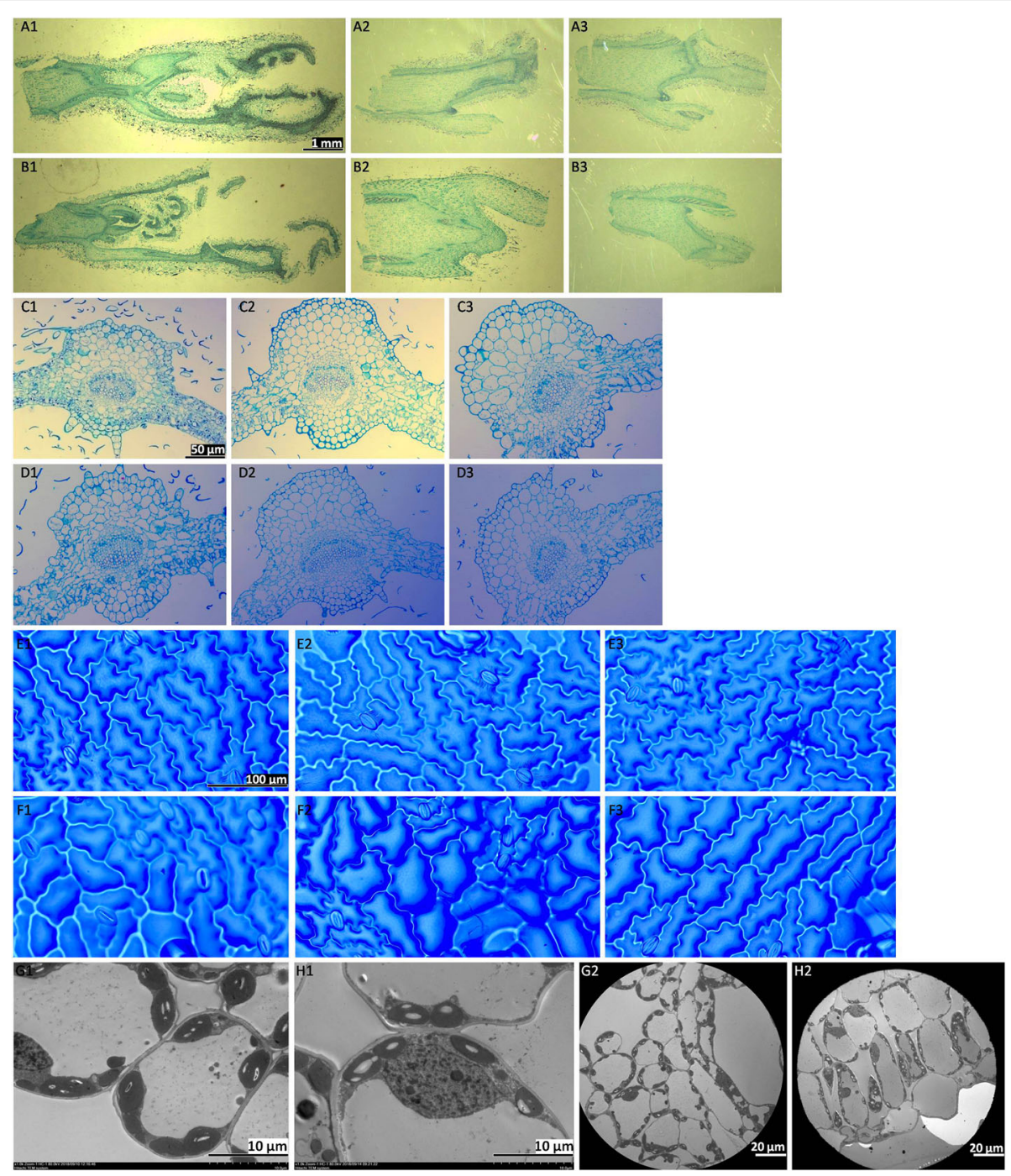

Fig. 2 Microscopic examinations of bud $(A, B)$ and leaf $(C-H)$ characteristics under two different temperatures. Paraffin sectioning pictures of bud at $25^{\circ} \mathrm{C}$ (TB:A1, TAB:A2; $\left.L A B: A 3\right)$ and $35^{\circ} \mathrm{C}$ (TB:B1, TAB:B2; $\left.\mathrm{LAB}: B 3\right)$. Paraffin sectioning pictures of leaf cross section at $25^{\circ} \mathrm{C}(\mathrm{TBL}: \mathrm{C} 1, \mathrm{MBL}: \mathrm{C2} ; \mathrm{LBL}: \mathrm{C} 3)$ and $35^{\circ} \mathrm{C}$ (TBL:D1, MBL:D2; LBL:D3). Leaf outer surface pictures at $25^{\circ} \mathrm{C}$ (TBL:E1, MBL:E2; LBL:E3) and $35^{\circ} \mathrm{C}$ (TBL:F1, MBL:F2; LBL:F3). Transmission electron micrographs at $25 \circ \mathrm{OC}(\mathrm{TBL}: \mathrm{G} 1, \mathrm{G} 2)$ and $35^{\circ} \mathrm{C}(\mathrm{TBL}: \mathrm{H} 1, \mathrm{H} 2)$

\section{Preferential gene expression during bud outgrowth}

Stage specificity (SS) algorithm was applied, with SS score greater than or equal to 0.05 , to point out the genes expressed commonly and specifically at a particular bud position in both the temperatures. Due to huge number of data, only those genes were selected with FPKM $\geq 5$. A total of 15,144,15,127 and 14,791 genes were found to be common in TB, TAB and LAB, respectively, at both the temperatures (Fig. 3a). However, 339 genes were expressing specifically in $\mathrm{TB}$ at $25^{\circ} \mathrm{C}$ and 581 at $35^{\circ} \mathrm{C} ; 391$ and 559 were specific to $\mathrm{TAB}$ at $25^{\circ} \mathrm{C}$ and $35^{\circ} \mathrm{C}$, respectively; 1043 and 336 were defined as specific to $\mathrm{LAB}$ at $25^{\circ} \mathrm{C}$ and $35^{\circ} \mathrm{C}$, respectively (Fig. 3b).

A heatmap showing the stage-specific expression of genes in chrysanthemum axillary buds is shown in Fig. 3c.
The analysis of gene ontology (GO) enrichment of all the specifically expressed genes at two different temperatures exhibited the genes mainly related to metabolic processes, response to stress, growth regulation, transport, organogenesis, cell cycle, cell division and hormonal regulation (Fig. 3d). These processes are well established as integral regulators of bud growth and development.

\section{Differentially expressed gene sets between $25^{\circ} \mathrm{C}$ and $35^{\circ} \mathrm{C}$ at different bud positions}

A total of 3366, 3280 and 3291 genes were up-regulated in $\mathrm{TB}, \mathrm{TAB}$ and $\mathrm{LAB}$, respectively; while, 4653,3714 and 6061 genes were down-regulated in $\mathrm{TB}, \mathrm{TAB}$ and $\mathrm{LAB}$, respectively. A significant number of transcription factors were also detected as differentially expressing, 


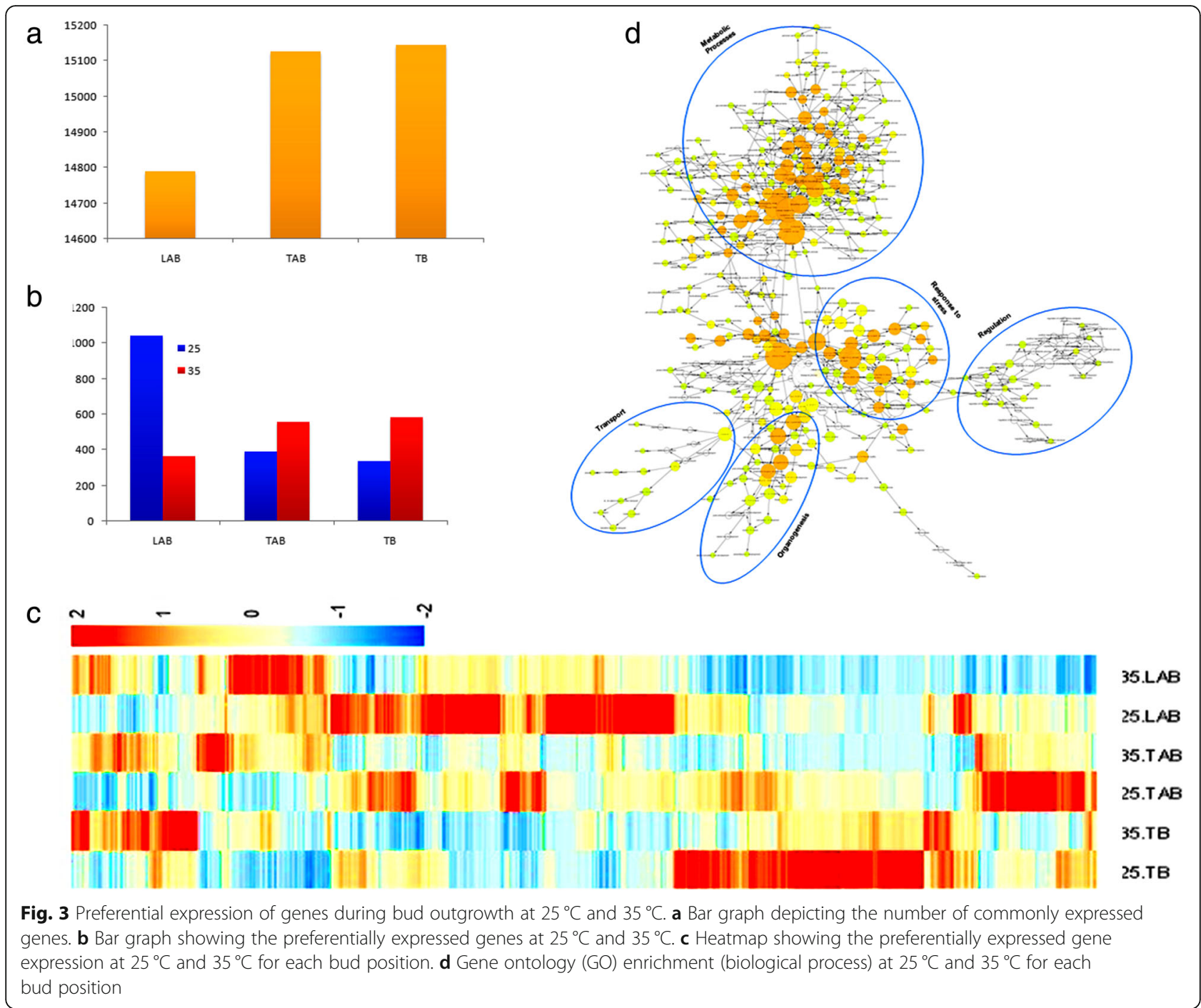

including 2244, 2191 and 2140 up-regulated TFs in TB, TAB and LAB, respectively; and 2857, 2427 and 3949 down-regulated TFs in $\mathrm{TB}, \mathrm{TAB}$ and $\mathrm{LAB}$, respectively (Fig. 4a). Top axillary position offers the nascent buds appearing under different temperatures; therefore, focusing on the TABs can give a better idea about the effect of high temperature. TFs were specifically analyzed for this stage (Fig. 4b). Plenty of TF families exhibited differential expression in $\mathrm{TAB}$, suggesting diverse functions during bud outgrowth (Fig. 4b). Major TF families include, ARF, B3, ERF, GRAS, MIKC_MADS, MYB, NAC, WRK and TCP. Presence of these families point out the involvement of divers activities including, cell differentiation (ARF), hormonal signalling pathways (ARF), cytokinin signalling (ARR-B). These families showed upregulation in $35^{\circ} \mathrm{C}$ as compared to $25^{\circ} \mathrm{C}$. WRK, the important transcriptional factor family for stress responses, showed significant up-regulation in response to high temperature in $\mathrm{TAB}$.
The GO enrichment analysis of DEGs in different bud positions pointed out a number of biological processes uniquely overrepresented at TB, TAB and LAB. Different terms related to cell division, cell cycle and cell growth were significantly enriched in the genes with elevated expressions at TAB. Similarly, GO terms associated with cellular components were also showing high expression at Tab. A wide range of GO terms were evident at all stages of bud outgrowth, including organogenesis, DNA replication, phosphorylation, hormonal responses, sucrose metabolism, transport, regulation of shoot development, photosynthesis etc. (Fig. 4c).

To ascertain the metabolic pathways responsible for bud outgrowth at TAB, the expression profiles of DEGs were overlaid onto the already known metabolic pathways using MapMan tool (Fig. 4d). Differential activity was observed about certain metabolic pathways at $\mathrm{TAB}$ under contrasting temperatures. Considerable differences were seen, under both the temperatures, in the 


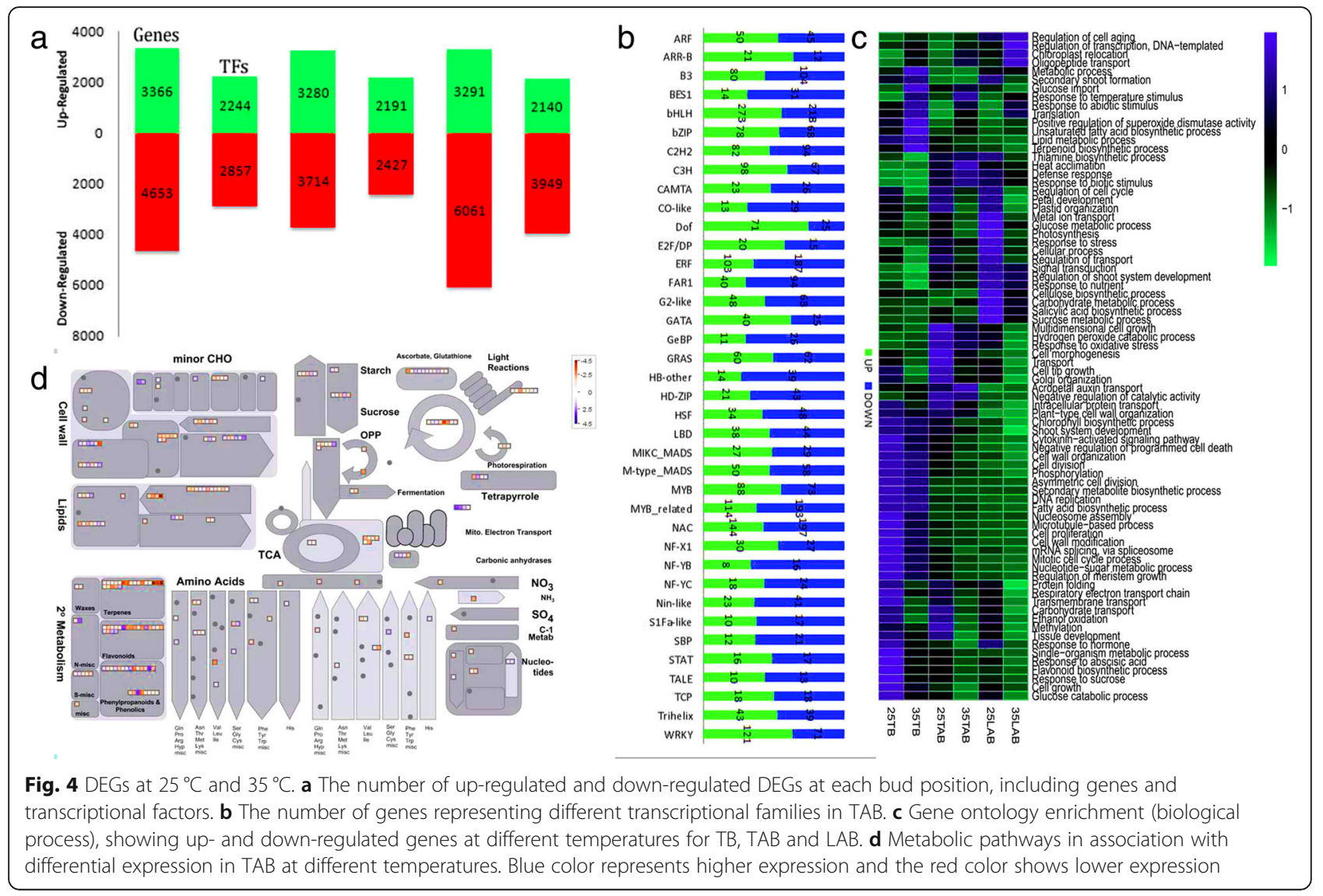

activity of the genes responsible for starch biosynthesis, especially the sucrose metabolism. Moreover, hormonal pathways were also evident in the temperature responses in $\mathrm{TAB}$, including the signalling for auxin, cytokinins and abscisic acid. The genes governing the starch metabolism and photosynthesis were also active in TAB at high temperature (Fig. 4d). A significant proportion of cell wall related genes expressed at higher levels in normal temperature top axillary buds, suggesting higher cell activity at suitable ambient environment than that of higher temperature, where temperature fluctuations beyond a normal range can hinder a range of cell activities.

\section{Hormonal networks are also involved in temperature sensing for bud kinetics}

A number of genes were identified involving in auxin biosynthesis and signalling with significant different set of expressions at $25^{\circ} \mathrm{C}$ and $35^{\circ} \mathrm{C}$ (Fig. 5b). Some of the candidate genes already known for auxin control have also been mined through sequencing data, including PIN, IAA, YUCCA, SKP2A and CUL1. Most of the genes are showing high expression in $25^{\circ} \mathrm{C}$ as compared to $35^{\circ} \mathrm{C}$. Similar results can be seen in the case of cytokinins wherein most of the genes exhibited high expression values in normal temperature regime as compared to high temperature (Fig. 5c).

The transcriptome analysis also depicted a role played by these hormones in axillary buds at two different temperature regimes (Fig. 5a). However, the role of strigolactone and $\mathrm{ABA}$ related genes was different from those of auxin and cytokinins related genes (Fig. 5d). ABA related genes exhibited quite high expression (a measure of FPKM value) in high temperature samples as compared to normal temperature. Fluctuations at TAB for IAA and CK at high temperature are obvious as compared to normal temperature (Fig. 5; IAA, CK). However, the expression intensity and difference was prominent in top axillary buds which are the most probable sites for receiving high temperature influence. Significantly high expression intensities of ABA related genes are obvious at top axillary buds, showing that high temperature reception was negatively expressed at top axillary sites to restrict bud outgrowth. However, the differences are considerable at other bud positions, including top buds and lower axillary buds. High $\mathrm{ABA}$ concentration at $\mathrm{TB}$ and $\mathrm{TAB}$ at high temperature suggests thermal regulation of bud through ABA (Fig. 5ABA). 


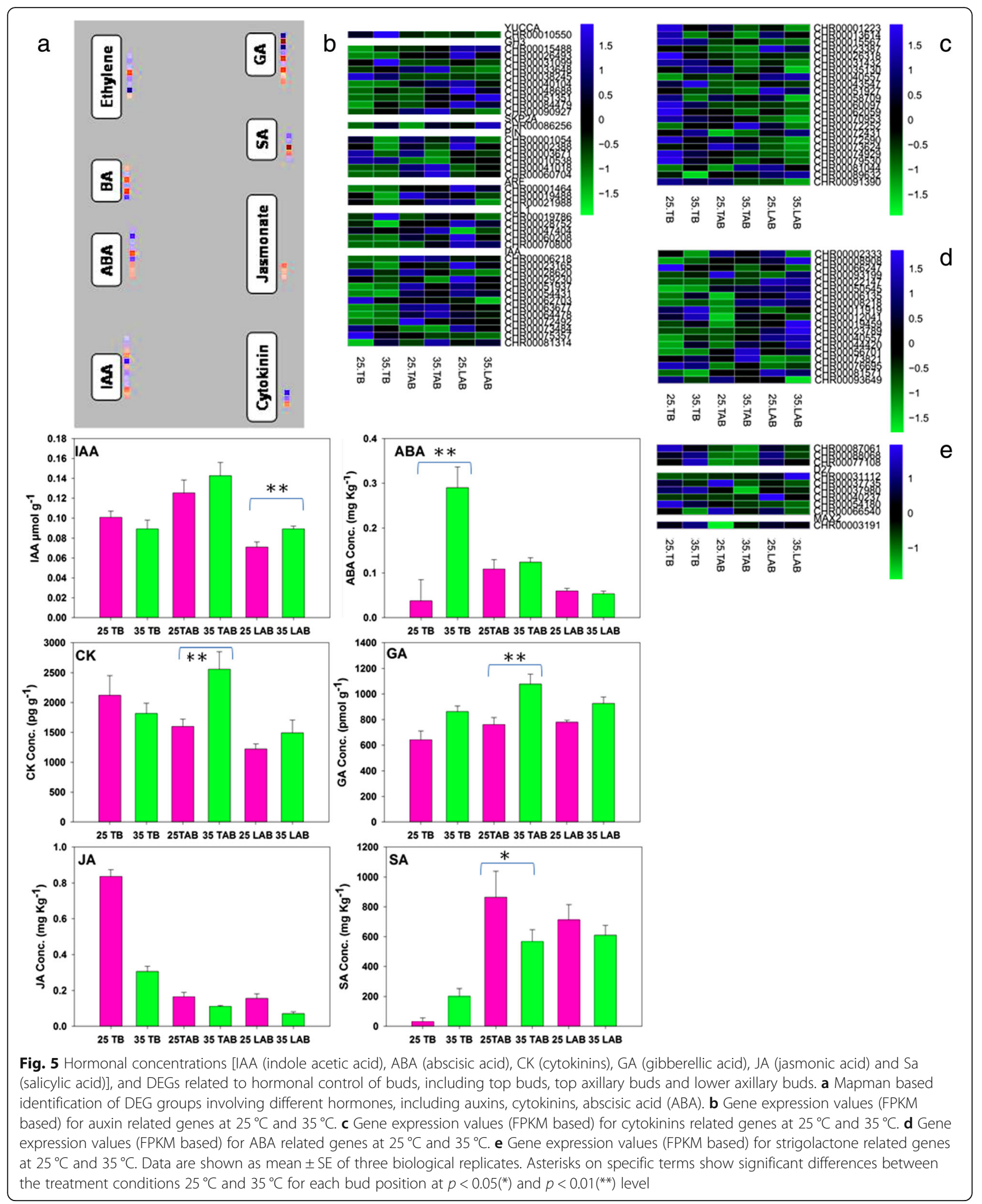


Some genes were found related to strigolactone (Fig. $5 e)$. The difference was not very significant between two temperatures. However, relatively high gene expression was seen in two candidate genes (D27 and MAX2) at $35^{\circ} \mathrm{C}$ as compared to $25^{\circ} \mathrm{C}$.

\section{Identification of coexpressed gene modules for selected morphological leaf and bud traits}

To understand the gene regulatory networks during bud outgrowth, we performed weighted gene coexpression network analysis (WGCNA) in association with leaf characteristics (leaf area and photosynthetic rate) and bud characteristics (bud length and sucrose concentration) (Fig. 6). The genes showing a FPKM $\geq 1$ were considered for this analysis due to large amount of data. A total of 24 modules were observed for bud outgrowth at contrasting temperatures (Fig. 6). Among these modules, MEdarkorchid3 was the most prominent in representing highly upregulated genes involved in leaf area and budsucrose and length manipulations. Some modules exhibited strong responses for bud length, including MEdarkorchid3, MEantiquewhite1, MEgreen2, MEroyalblue 1, MEtan3 and MEdarkgoldenrod (Fig. 6). However, the rate of photosynthesis and the leaf area were only prominent in MEroyalblue 1 and MEdarkorchid3, respectively. In the case of sucrose, high expression modules included MEdarkorchid3, MEantiquewhite1, MErosybrown3 and MEgreen2, suggesting the involvement of sugar homeostasis in bud kinetics.

Hub genes were identified using Cytoscape for MEantiquewhite1 (trpC and GRR1) (supplementary Fig. 3) and MEGreen2 (UBC12 and CYP17) (supplementary Fig. 4). All bud positions showed difference for these hub genes at different temperatures. However, the significant differences can be seen at lower axillary buds (supplementary Fig. 5). The trpC plays role in cell wall synthesis and the GRR1 works in auxin biosynthetic pathway. UBC12 acts as an enzyme in auxin biosynthetic pathways and the CYP17 plays a role in steroid hormone biosynthesis.

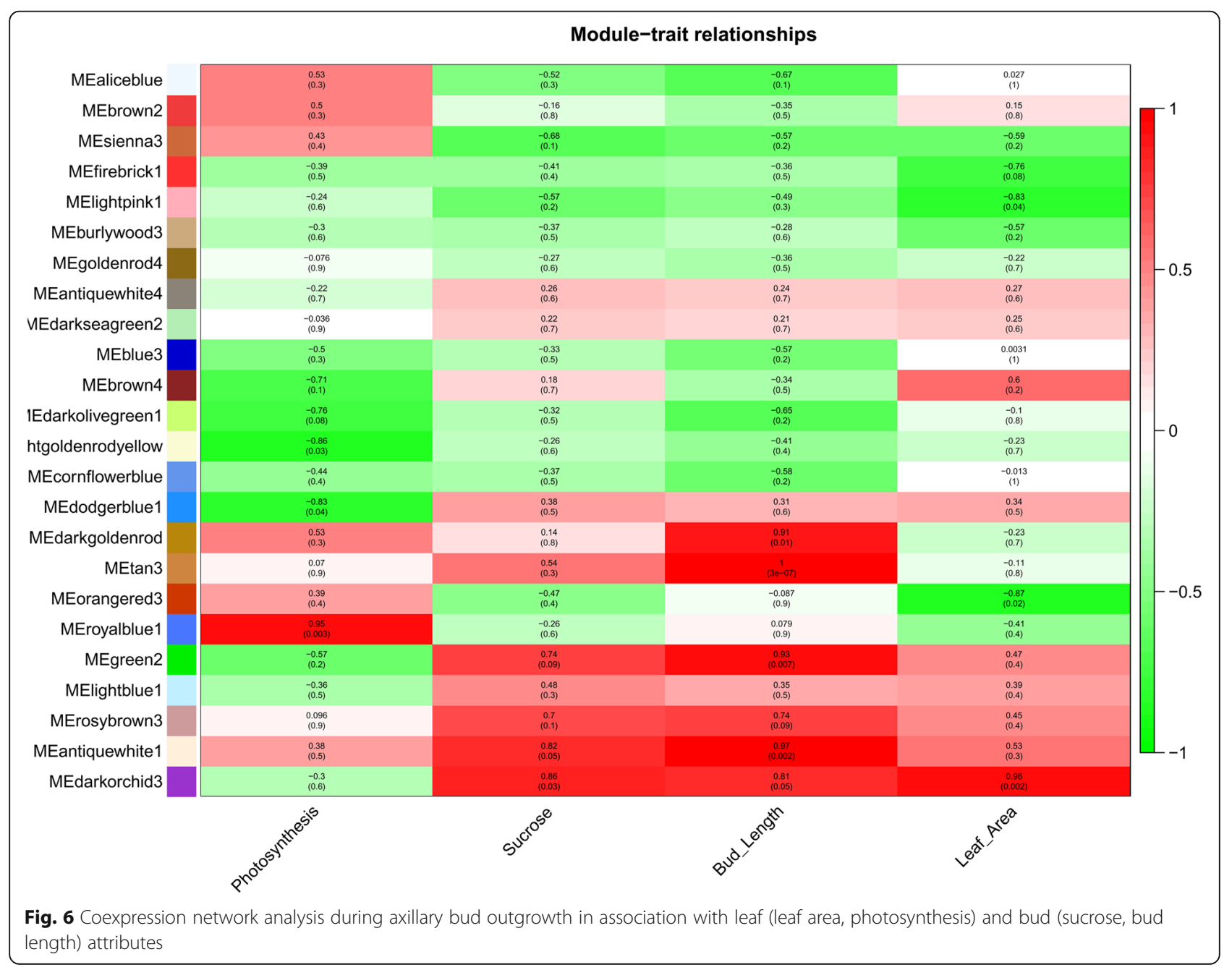




\section{Discussion}

The molecular regulation for the axillary bud outgrowth is poorly defined in chrysanthemum while the success of cut chrysanthemum solely depends on the vigor of single stalk devoid of axillary branches. However, so far, the efforts to nullify branching have not yet been successful due to unavailability of a profound regulatory network to knock out. We used leaf morpho-physiological indicators and RNA-seq approach from axillary buds to ascertain the transcriptome dynamics at three bud positions influenced by contrasting temperature regimes. A considerable proportion of chrysanthemum genes were shown to be expressed in at least one of the bud positions. High throughput RNA-Seq facilitated the mining of new genes with differential expression profiles. The expression information around the three bud positions exhibited significant reproducibility at two temperatures and each bud position was distinguished from the other in the principal component analysis, suggesting prominent gene expression changes among bud stages. The comprehensive analysis of transcriptome data along with coexpression networks pointed out a number of specific and coregulated transcriptional plans associated with different bud outgrowth stages. Moreover, sucrose, hormonal contents and the morpho-physiological indicators from leaf also strengthened the deep impact of temperature on the axillary bud sites.

In the temperate zone, the bud burst is caused mainly by temperature [37, 38]. The tillering extent can affect leaf area, plant density and the light interception [2]. In our study, leaf area was narrowed down by high temperature (Fig. 1). Bud development starts with the initiation of meristem [12] and then at a certain transition stage, the outgrowth fate is driven by intrinsic and extrinsic factors $[39,40]$. A plant may be unable to develop an axillary growth due to malformation of meristem or outgrowth inhibition of axillary buds [41].

Environmental fluctuations may trigger differential expression of certain miRNAs to compete with stress conditions [42]. Some of miRNAs have been identified in plants related to stress, including drought [43], nutrient deficiency [44], heat [45] and cold [46]. Most of the plants can adjust their biochemical and physiological processes by fluctuating proline contents, MDA, hydrogen peroxide and sucrose contents to manage temperature variations [47, 48]. Interesting fluctuations were observed in ROS and antioxidant species in leaves at $35^{\circ} \mathrm{C}$ as compared to $25^{\circ} \mathrm{C}$. However, most of them showed high values in lower bud leaves as compared to top bud leaves in normal temperature. The chloroplast is a potent sensor for stress responses and environmental changes [49]. Slight movement of chloroplast can be seen in leaves under $35^{\circ} \mathrm{C}$ (Fig. $2 \mathrm{~g}, \mathrm{~h}$ ).
Temperature elevation beyond a certain limit negatively affects plant growth by delaying growth and several gene units can be involved [42]. For example, temperature stress can disturb the nutrient balance, hormonal and metabolic homeostasis in plants [50, 51], thereby impacting the regulatory machinery behind bud outgrowth. Temperature change modifies the hormonal levels inside the plant body [52]. ARFs are the transcriptional factors that control the expression of genes induced by auxin through their binding to ARPs (auxinresponsive promoters) [53].

Researchers have shown that bud outgrowth status is controlled by numerous factors, including mainly the growth promoters such as sugars, cytokinins and inhibitors like auxin, ABA and strigolactone [11, 12, 54-58]. Relatively high amounts of ABA at top buds and top axillary buds suggest high temperature control of axillary buds by ABA (Fig. 5). However, higher IAA concentrations at $\mathrm{TAB}$ and $\mathrm{LAB}$ at $35^{\circ} \mathrm{C}$ point more movement of auxin from top buds towards lower bud positions as compared to normal temperature (Fig. 5). Through decades of research, a group of genes expressing in sorghum buds (i.e., GT1/BRC1/TB1/MAX2) has been identified to repress bud outgrowth until environmental cues, cytokinins and sugar signaling are permissible for axillary bud outgrowth [2]. Strigolactones are the key controllers of axillary shoots that unite to DAD2/MAX2: D14 complex and work through GT1/BRCI/TB1 pathway [12]. MAX2 inhibits bud outgrowth through encoding an F-box protein [13, 14]. RwMAX, from rose, was downregulated by sucrose supplies [11]. In stem, the level of cytokinins is degraded by auxin-induced downregulation of cytokinins biosynthesis gene, whereas abscisic acid (ABA) expresses an auxin-independent inhibition of bud outgrowth [17, 54, 59]. In our study, high expression of MAX2 at $\mathrm{TAB}$ at $35^{\circ} \mathrm{C}$ shows strigolactone-mediated inhibition of axillary sites by high temperature (Fig. 5e).

The differential increase in bud length at different positions suggested the differential role of two temperatures in cell division. The gene ontology enrichment analysis shows high rate (higher FPKM) of cell cycle and cell division in normal temperature especially at TAB. The extended mitosis can be seen at normal temperature. High mitotic activity causes higher gluconeogenesis, resulting in increased seed size [60]. We noted considerable transcriptional activity of genes for cell growth, cell cycle, heat stress and GO enrichment, showing significant differences at both the temperatures (Fig. 4). Moreover, several genes related to cell expansion, storage compounds and fatty acid biosynthesis shown higher transcriptional activity for normal temperature (Fig. 4c). A number of TF families are studied to be involved in organ development [61-63]; 
however, a few of them are considered to be involved in temperature-induced bud outgrowth. Our study found plenty of TFs to be involved in differential bud outgrowth at contrasting temperatures, especially at TABs. Some known TF families were shown among the differentially expressing TFs; however, the exact function is still unclear for most of these genes. Some known TF families, for example NAC, ARF and WRKY, which expressed differently at two temperature regimes, are well established in their role in organ development [7, 61-64]. Differential expression intensities of same family members at different bud positions and different temperatures may involve different regulatory pathways, thereby determining position-specific bud development. To get better understanding of this, we used coexpression network analysis to mine unique and common gene groups associated with bud outgrowth at contrasting temperatures.

Ascertaining the transcription modules can disclose gene regulatory networks governing biological processes linked with bud and seed development [2, 7, 42, 65]. Therefore, we created transcription modules (by connecting transcriptional factors with their respective binding motifs and coexpressed target genes) for top axillary buds which are considered to be the crucial bud outgrowth stage to study temperature influence. Although an extensive overlap was observed for TAB at $25^{\circ} \mathrm{C}$ and $35^{\circ} \mathrm{C}$, there were several components pertinent to a specific transcriptional accumulation, suggesting uniqueness of the transcription modules for each temperature regime. The modules with opposite expression genes were mainly concerned with cell cycle, growth, cell size, histone modification and energy. Several components of these modules have previously been implicated in different aspects of bud and seed development [2, 65-70]. Thus, our study demonstrated that transcriptional module construction along with coexpression networks can do a great deal to comprehend the inherent mechanism governing agronomic traits of bud outgrowth. However, further studies about each network member are needed to elucidate the whole diagram of GRNs.

\section{Conclusion}

The regulation of axillary bud by environmental and hormonal signals is well established; however, their inherent mechanisms are largely unknown in chrysanthemum. Studying high temperature as a vital factor inhibiting but outgrowth provides a much better understanding of how stooling is controlled during plant growth. In the present study, RNA-Seq data coupled with morpho-physiological integrators from three bud positions at two temperature regimes brings a robust source to understand bud outgrowth status influenced by high temperature in cut chrysanthemum. Our results provided the evidence that different bud positions exhibited relative susceptibility towards temperature changes, especially the top axillary buds showed distinguished response for high temperature in chrysanthemum. Our results showed that photosynthetic leaf area, physiological indicators, hormonal fluctuations and sucrose utilization are significantly changed, indicating that they were involved in inhibiting the axillary bud outgrowth by high temperature. Transcriptomic comparison revealed amount of bud position-specific expression gene sets. Using WGCNA, we identified important modules highly associated with morphological leaf and bud traits. Our results provide helpful information for elucidating the regulatory mechanism of temperature on axillary bud growth in chrysanthemum.

\section{Methods}

\section{Plant material and growth conditions}

Cuttings of the Chrysanthemum morifolium variety 'Jinba' were obtained from the Chrysanthemum Germplasm Resource Preserving Nursery (Beijing Forestry University, Beijing, China). Cuttings of uniform length, containing at least two buds were obtained from mother plant and were grown in $50 \mathrm{H}$-Cutting tray Drip trays in the greenhouse of Beijing Forestry University. After 20 days, the seedlings were grown into pots. Two month old seedlings at 15 axillary bud stage were transferred to controlled temperature chambers fitted with uniform light (Philips T8 TLD36/33 cold white tube, $120 \mu \mathrm{mol}$ $\mathrm{m}^{-2} \mathrm{~s}^{-1}$ optical density). One of the chambers was set to day and night temperature of $35 / 25^{\circ} \mathrm{C}$, respectively, and was regarded as high temperature regime. The other chamber was set to $25 / 15^{\circ} \mathrm{C}$ and was regarded as normal temperature regime. Both the chambers were provided with equal light intensities with a day to night duration of $16 / 8 \mathrm{~h}$. A total of 45 plants were kept in each of the high and normal temperature chambers.

\section{Sampling procedure}

After 11 days of growth in contrasting temperatures, the sampling was performed from top buds (TB), top axillary buds (TAB) and lower axillary buds (LAB). The sampling portion was the rectangular stem portion including the axillary bud (Fig. 1). The leaves around the top bud were regarded as the top bud leaves (TBL) and those around top and lower axillary buds as middle bud leaves (MBL) and lower bud leaves (LBL), respectively. Leaf samples were also collected along with bud samples for physiological indices. Single repeat included sampling from 15 plants, containing $15 \mathrm{TBs}, 45 \mathrm{TABs}$ and 45 LABs. Thus, three repeats were collected from 45 plants in each temperature regime. Sampling was done in three biological repeats. Samples were collected in liquid 
nitrogen and stored at $-80^{\circ} \mathrm{C}$ until RNA extraction or physiological analyses.

\section{Morphological parameters \\ Bud length}

Bud length $(\mathrm{mm})$ was measured every week using digital Vernier calipers.

\section{Leaf area $\left(\mathrm{cm}^{2}\right)$}

After 11 days of growth under contrasting temperatures, top leaf, top axillary leaf and lower axillary leaf were scanned along with proper scale. Scanned pictures were used to measure leaf area by ImageJ software [71].

\section{Wet to dry mass ratio}

Top bud leaf (TL), middle bud leaf (MBL) and the lower bud leaf (LBL) were selected from 11 days old plants and weighted initially to note the wet weights. The leaves were packed in paper and kept overnight in an incubator set to $65^{\circ} \mathrm{C}$. Crack-dried leaves were weighted again to take the dry weights. Wet to dry ratios were calculated by dividing the wet weight of each leaf to its dry weight.

\section{Gas exchange and photosynthetic pigments}

Net rate of photosynthesis (Pn), water conductance $(\mathrm{Cw})$, intercellular $\mathrm{CO}_{2}$ concentration $(\mathrm{Ci})$ and transpiration rate $(\mathrm{E})$ were measured using a portable measuring system (Ecotek, China). The environmental parameters were: leaf temperature $25^{\circ} \mathrm{C}$, relative air humidity $80 \%$, $1200 \mu \mathrm{mol} \mathrm{m}^{-2} \mathrm{~s}^{-1}$ photosynthetic photon flux density (PPFD) and $400 \pm 5 \mu \mathrm{mol} \mathrm{mol}^{-1}$ of ambient $\mathrm{CO}_{2}$ concentration.

Chlorophyll pigments were measured using the method of Zhang [72] with little modification. Briefly, 1 $\mathrm{g}$ of leaf sample was homogenized in $80 \%(\mathrm{v} / \mathrm{v})$ acetone solution, followed by centrifugation at $10,000 \mathrm{~g}$ for 10 $\min$ at $4{ }^{\circ} \mathrm{C}$. The supernatant was collected to measure absorbance at 663,645 and $470 \mathrm{~nm}$ to measure chlorophyll a (Chl a), chlorophyll b (Chl b), carotenoids (Caro), and total chlorophyll $(\mathrm{Chl})$ considering the calculations by Lichtenthaler [73].

\section{Physiological indices}

Protein, Malondialdehyde contents and the antioxidant enzyme activities were measured following the protocol by Chen and Zhang [74].

\section{Stomatal density}

Stomatal density was measured following the procedure described by Hopper et al. [71]. Stomatal density was ascertained using ImajeJ (National Institutes of Health, Bethesda, MD, USA) applying the plug-in of cell counter [75].
Microscopic documentation of axillary buds under

different temperature regimes

Paraffin sectioning

Stem cuttings containing single axillary buds were excised to see bud activities at micro level. After every $24 \mathrm{~h}$ the buds were fixed in FAA (formalin-acetic acidalcohol) containing 70\% ethanol, 37\% formaldehyde acetic acid at a ratio of 18:1:1. Buds were then dehydrated using butyl alcohol series and embedded in paraffin. Embedded samples were cut into $10 \mu \mathrm{m}$ thick strips using rotary microtone and then placed on microscopic slides. Slides were kept overnight at $40^{\circ} \mathrm{C}$ and stained in Safranin-O and fast-green staining series (Kebrom and Mullet, 2015) and were mounted using few drops of Permount medium (Fisher Scientific, Waltham, MA, USA). The slides were covered with cover glass and observed using a bright-field microscope.

\section{Transmission electron microscopy}

Top axillary leaf mesophyll cells were anatomically analyzed using transmission electron microscopy [76, 77]. 2 $\mathrm{mm}^{2}$ leaf sections were cut parallel to the midrib and immersed in $2.5 \%(\mathrm{v} / \mathrm{v})$ glutaraldehyde solution. The solution was then replaced with fresh fixative. After proper washing, the samples were fixed in $1 \% \mathrm{OsO}_{4}(\mathrm{w} / \mathrm{v})$ with $\mathrm{K}_{3} \mathrm{Fe}(\mathrm{CN})_{6}$ in $0.1 \mathrm{M}$ Sodium carbohydrate buffer. Successive ethanol series were run to dry the samples (including staining with $2 \%$ uranyl acetate at $50 \%$ ethanol step), followed by embedding in Spurr's resin. Extremely thin sections were cut using an ultramicrotome (Leica EM UC6). These sections were further stained with uranyl acetate and lead citrate. Sections were finally viewed with a high definition transmission electron microscope (Tecnai 12, Philips, The Netherlands).

\section{Measurement of sucrose concentration}

The concentration of sucrose was estimated following the methodology of Yuan et al. [78] with slight modification. In short, buds were finely ground in liquid nitrogen and extracted three times (at $80^{\circ} \mathrm{C}$ ) in $80 \%$ ethyl alcohol. The pooled supernatants were filtered using carbon black, making a final volume of $25 \mathrm{ml}$ by adding distilled water into filtrate. The reaction mixture contained $100 \mu \mathrm{l}$ of $2 \mathrm{~N} \mathrm{NaOH}$ and $900 \mu \mathrm{l}$ of extract. This solution was boiled at $99^{\circ} \mathrm{C}$ in a water bath for $10 \mathrm{~min}$, followed by cooling for $5 \mathrm{~min}$. After that, $1 \mathrm{ml}$ of $0.1 \%$ resorcinol and $3 \mathrm{ml}$ of $10 \mathrm{~N} \mathrm{HCl}$ were added to this reaction mixture and heated at $80^{\circ} \mathrm{C}$ for $1 \mathrm{~h}$. Absorbance was observed at $480 \mathrm{~nm}$ using a UV-1700 PharmaSpec spectrophotometer (Shimadzu Corporation, Kyoto, Japan). Sucrose solution of $20 \mu \mathrm{g} / \mathrm{ml}$ was used to obtain a standard curve at a proper correlation coefficient $\left(R^{2}=0.998\right)$. 


\section{Analysis of hormones}

Major hormones related to bud outgrowth were analysed with HPLC-MS/MS (Aglient) as described by Pan et al. [79].

\section{RNA-seq library preparation and sequencing}

Total RNA was extracted from frozen buds using MiniBESTplant RNA extraction kit (TaKaRa) including DNA removal as well, finally obtaining DNA-free RNA. All the 18 libraries (6 samples in three biological replicates) were sequenced on Illumina platform (HiSeq 2000) to produce paired-end sequence reads of 150-nucleotide long. The raw data were analyzed to understand various parameters and the high-quality reads were sorted with NGS QC Toolkit (v2.3). The quality reads were mapped on the Chrysanthemum nankingense genome [1] using TopHat (v2.0.0) with default parameters. FPKM (fragments per kilobase of transcript length per million mapped reads) values were obtained for all the genes in each sample by processing the mapped data through Cufflinks (v2.0.2). Spearman correlation coefficient (SCC) was applied to determine the correlation between the biological repeats. Principal component analysis (PCA) and hierarchical clustering were executed using prcomp and corrplot utilities of R package [7]. Differential expression was ascertained between the samples using Cuffdiff and the genes showing at least twofold difference in expression with a corrected $P$-value $(q$ value) of $<0.05$ after the adjustment of false discovery rate. Stage specificity (SS) scoring algorithm was used to identify preferentially expressed/stage-specific genes. SS scoring algorithm identifies stage-specific gene by comparing the expression of that genes in a specific stage with its maximum expression value in other stages as explained in previous researches [7, 80]. Higher the SS score of gene in a given stage more significant is the expression of that gene at that stage. A selected set of genes was used to generate heatmap using pheatmap and ggplot2 utilities of $\mathrm{R}$.

\section{Gene ontology and pathway enrichment analysis}

GO enrichment analysis was performed for DEGs using BINGO plug-in of Cytoscape [7, 81]. For each GO term, the $P$-value was calculate and corrected using the error correction method by Benjamini Hoschberg [7]. The GO terms with $q$-value of $\leq 0.05$ were regarded as significantly enriched. MapMan (v3.6.0RC1) was used to generate pathway enrichment analysis of different gene sets with the best Arabidopsis (TAIR10) homolog.

\section{Weighted gene coexpression network analysis}

For the construction of coexpression modules, the WGCAN packages were used $[82,83]$. Using $\log _{2}(1+$ FPKM) values, a matrix containing pairwise SCCs between all gene pairs was produced, followed by transformation into an adjacency matrix using the following formula: adjacency value $=\mid(1+$ correlation $) /\left.2\right|^{\beta}$. $\beta$ shows soft threshold value for the correlation matrix, giving elevated weight to the strongest correlations while reserving inter-gene connectivity. A $\beta$ magnitude of 12 was chosen on the basis of scale-free criterion for topology described previously [7, 82]. Adjacency matrix, thus obtained, was changed to a TO (topology overlap) matrix through TOM similarity algorithm, followed by hierarchical clustering of genes on the basis of TO similarity. Hierarchical clustering dendrogram was cut via dynamic tree-cutting algorithm and the modules were defined by combining the branches to a stable number of clusters [83]. A summary profile called module eigengene (ME) was calculated for each module using PCA. Those modules were retained with higher $\mathrm{TO}$ value as compared to the TO values of randomly selected gene modules. GO enrichment analysis was performed for each module.

\section{Statistical analysis}

The data was analysed using One-way ANOVA in SPSS software (SPSS Inc., Chicago, IL, USA; ver. 16.0). Significant variations are indicated at $p<0.05$ or $p<0.01$ level.

\section{Supplementary information}

Supplementary information accompanies this paper at https://doi.org/10. 1186/s12870-020-02336-0.

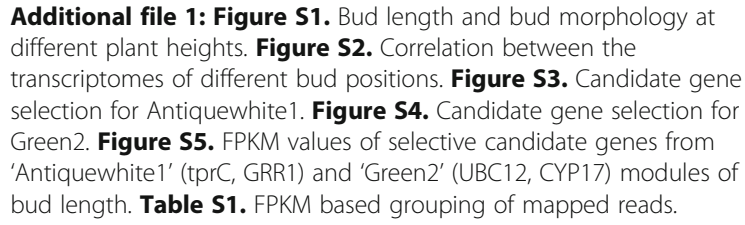

\section{Abbreviations}

ABA: Abscisic acid; Caro: Carotenoids; CAT: Catalase; Chl: Total chlorophyll; $\mathrm{Chl}$ a: Chlorophyll a; Chl b: Chlorophyll b; Ci: Intercellular $\mathrm{CO}_{2}$ concentration; CK: Cytokinins; Cw: Water conductance; DEGs: Differentially expressed genes; FAA: Formalin-acetic acid-alcohol; FPKM: Fragments Per Kilobase of transcript per Million mapped reads; GO: Gene ontology; IAA: Indole-3-acetic acid; MDA: Malondialdehyde; PCA: Principal component analysis; PIN: Pin-formed; Pn: Net rate of photosynthesis; POD: Peroxidase; PPFD: Photosynthetic photon flux density; ROS: Reactive oxygen species; SOD: Superoxide dismutase; TB: Top buds; TAB: Top axillary buds; LAB: Lower axillary buds; TFs: Transcription factors; TBL: Top bud leaf; MBL: Middle bud leaf; LBL: Lower bud leaf; WGCNA: Weighted Gene Co-expression Network Analysis

\section{Acknowledgments}

We are thankful to Nadia Sucha (Kingston University London) for suggesting professional native English speaker for our manuscript. We are also thankful to Xie Jianbo (Beijing Forestry University) for providing help in analyzing RNA-seq data for our manuscript.

\section{Authors' contributions}

SA, CY and QZ designed the experiments; SA, CY, YY and QY performed the experiments. SA wrote the manuscript; $C Y$ revised the manuscript. SA, CY, TC, JW and HP analyzed the data. All authors read and approved the final manuscript. 


\section{Funding}

This work was supported by the Fundamental Research Funds for the National Natural Science Foundation of China (No. 31700621) and Special Fund for Beijing Common Construction Project. Funding bodies were not involved in the design of the study and data collection, analysis, and interpretation of data and in writing the manuscript.

\section{Availability of data and materials}

The data sets are included within the article and its Additional files. The raw sequence data reported in this paper have been deposited in the NCBI under the BioProgect ID PRJNA608820. The raw sequence data are also available in the Genome Sequence Archive in BIG Data Center, Beijing Institute of Genomics (BIG), Chinese Academy of Sciences, under accession numbers CRA002314.

\section{Ethics approval and consent to participate}

Not applicable.

\section{Consent for publication}

Not applicable.

\section{Competing interests}

The authors declare that they have no competing interest.

Received: 13 November 2019 Accepted: 9 March 2020

Published online: 07 April 2020

\section{References}

1. Song C, Liu Y, Song A, Dong G, Zhao H, Sun W, Ramakrishnan S, Wang Y, Wang S, Li T. The Chrysanthemum nankingense genome provides insights into the evolution and diversification of chrysanthemum flowers and medicinal traits. Mol Plant. 2018.

2. Kebrom TH, Mullet JE. Transcriptome profiling of tiller buds provides new insights into phyB regulation of tillering and indeterminate growth in Sorghum. Plant Physiol. 2016;170(4):2232-50.

3. Leeggangers $H$, Nijveen $H$, Bigas JN, Hilhorst HW, Immink RG: Molecular regulation of temperature-dependent floral induction in Tulipa gesneriana. Plant Physiol 2017:pp. 01758.02016.

4. Bhandawat A, Singh G, Seth R, Singh P, Sharma RK. Genome-wide transcriptional profiling to elucidate key candidates involved in bud burst and rattling growth in a subtropical bamboo (Dendrocalamus hamiltonii). Front Plant Sci. 2017;7:2038

5. Fan Z, Li J, Li X, Wu B, Wang J, Liu Z, Yin H. Genome-wide transcriptome profiling provides insights into floral bud development of summerflowering Camellia azalea. Sci Rep. 2015;5:9729

6. Ni J, Zhao M-L, Chen M-S, Pan B-Z, Tao Y-B, Xu Z-F. Comparative transcriptome analysis of axillary buds in response to the shoot branching regulators gibberellin A3 and 6-benzyladenine in Jatropha curcas. Sci Rep. 2017:7(1):11417

7. Garg R, Singh VK, Rajkumar MS, Kumar V, Jain M. Global transcriptome and coexpression network analyses reveal cultivar-specific molecular signatures associated with seed development and seed size/weight determination in chickpea. Plant J. 2017;91(6):1088-107.

8. Porto DD, Bruneau M, Perini P, Anzanello R, Renou J-P, HPd S, Fialho FB. revers LF: transcription profiling of the chilling requirement for bud break in apples: a putative role for FLC-like genes. J Exp Bot. 2015;66(9):2659-72.

9. Rabot A, Henry C, Ben Baaziz K, Mortreau E, Azri W, Lothier J, Hamama L, Boummaza R, Leduc N, Pelleschi-Travier S. Insight into the role of sugars in bud burst under light in the rose. Plant Cell Physiol. 2012:53(6):1068-82.

10. Mason MG, Ross JJ, Babst BA, Wienclaw BN, Beveridge CA. Sugar demand, not auxin, is the initial regulator of apical dominance. Proc Natl Acad Sci. 2014;111(16):6092-7.

11. Barbier FF, Lunn JE, Beveridge CA. Ready, steady, go! A sugar hit starts the race to shoot branching. Curr Opin Plant Biol. 2015:25:39-45.

12. Janssen BJ, Drummond RS, Snowden KC. Regulation of axillary shoot development. Curr Opin Plant Biol. 2014;17:28-35.

13. Stirnberg P, Furner IJ, Ottoline Leyser H. MAX2 participates in an SCF complex which acts locally at the node to suppress shoot branching. Plant J. 2007:50(1):80-94

14. Stirnberg $P$, van De Sande $K$, Leyser HO. MAX1 and MAX2 control shoot lateral branching in Arabidopsis. Development. 2002;129(5):1131-41.
15. Crawford S, Shinohara N, Sieberer T, Williamson L, George G, Hepworth J, Müller D, Domagalska MA, Leyser O: Strigolactones enhance competition between shoot branches by dampening auxin transport. Development 2010:dev. 051987.

16. Domagalska MA, Leyser O. Signal integration in the control of shoot branching. Nat Rev Mol Cell Biol. 2011;12(4):211.

17. Chatfield SP, Stirnberg P, Forde BG, Leyser O. The hormonal regulation of axillary bud growth in Arabidopsis. Plant J. 2000;24(2):159-69.

18. Faust JE, Heins RD. High night temperatures do not cause poor lateral branching of chrysanthemum. Hort Science. 1992;27(9):981-2

19. Yang J, Chen X, Zhu C, Peng X, He X, Fu J, Ouyang L, Bian J, Hu L, Sun X. RNA-seq reveals differentially expressed genes of rice (Oryza sativa) spikelet in response to temperature interacting with nitrogen at meiosis stage. BMC Genomics. 2015;16(1):959.

20. Prasad P, Boote K, Allen L Jr, Sheehy J, Thomas J. Species, ecotype and cultivar differences in spikelet fertility and harvest index of rice in response to high temperature stress. Field Crop Res. 2006:95(2-3):398-411.

21. Jagadish S, Muthurajan R, Oane R, Wheeler TR, Heuer S, Bennett J, Craufurd $\mathrm{PQ}$. Physiological and proteomic approaches to address heat tolerance during anthesis in rice (Oryza sativa L.). J Exp Bot. 2009;61(1):143-56.

22. Matsui T, Omasa K. Rice (Oryza sativa L.) cultivars tolerant to high temperature at flowering: anther characteristics. Ann Bot. 2002;89(6):683-7.

23. Endo M, Tsuchiya T, Hamada K, Kawamura S, Yano K, Ohshima M, Higashitani A, Watanabe M, Kawagishi-Kobayashi M. High temperatures cause male sterility in rice plants with transcriptional alterations during pollen development. Plant Cell Physiol. 2009;50(11):1911-22.

24. Zhang X, Li J, Liu A, Zou J, Zhou X, Xiang J, Rerksiri W, Peng Y, Xiong X, Chen $X$. Expression profile in rice panicle: insights into heat response mechanism at reproductive stage. PLoS One. 2012;7(11):e49652.

25. Kelliher $\mathrm{T}$, Egger $\mathrm{RL}$, Zhang $\mathrm{H}$, Walbot $\mathrm{V}$. Unresolved issues in pre-meiotic anther development. Front Plant Sci. 2014;5:347.

26. Asada K. The water-water cycle in chloroplasts: scavenging of active oxygens and dissipation of excess photons. Annu Rev Plant Biol. 1999;50(1):601-39.

27. Ahmad P, Jaleel CA, Salem MA, Nabi G, Sharma S. Roles of enzymatic and nonenzymatic antioxidants in plants during abiotic stress. Crit Rev Biotechnol. 2010:30(3):161-75.

28. Ahmad P, Nabi G, Jeleel C, Umar S: Free radical production, oxidative damage and antioxidant defense mechanisms in plants under abiotic stress. Oxidative stress: role of antioxidants in plants Studium Press, New Delhi 2011:19-53.

29. Hodges DM, DeLong JM, Forney CF, Prange RK. Improving the thiobarbituric acid-reactive-substances assay for estimating lipid peroxidation in plant tissues containing anthocyanin and other interfering compounds. Planta. 1999:207(4):604-11

30. Koyro H-W, Ahmad P, Geissler N: Abiotic stress responses in plants: an overview. In: Environmental adaptations and stress tolerance of plants in the era of climate change. Springer; 2012: 1-28.

31. Liu W, Yu K, He T, Li F, Zhang D, Liu J. The low temperature induced physiological responses of Avena nuda L., a cold-tolerant plant species. Sci World J. 2013;2013:7

32. Kochhar S, Watkins CB, Conklin PL, Brown SK. A quantitative and qualitative analysis of antioxidant enzymes in relation to susceptibility of apples to superficial scald. J Am Soc Hortic Sci. 2003;128(6):910-6.

33. Hall CR, Dickson MW. Economic, environmental, and health/well-being benefits associated with green industry products and services: a review. J Environ Hortic. 2011;29(2):96-103.

34. Teixeira da Silva J. Tissue culture and cryopreservation of chrysanthemum: a review. Biotechnol Adv. 2003:21:715-66.

35. Savicka M, Škute N. Effects of high temperature on malondialdehyde content, superoxide production and growth changes in wheat seedlings (Triticum aestivum L.). Ekologija. 2010;56(1):26-33.

36. Kebrom TH, Mullet JE. Photosynthetic leaf area modulates tiller bud outgrowth in sorghum. Plant Cell Environ. 2015;38(8):1471-8.

37. Chuine I. A unified model for budburst of trees. J Theor Biol. 2000;207(3): 337-47.

38. Kramer K, Leinonen I, Loustau D. The importance of phenology for the evaluation of impact of climate change on growth of boreal, temperate and Mediterranean forests ecosystems: an overview. Int J Biometeorol. 2000; 44(2):67-75

39. Shimizu-Sato $\mathrm{S}$, Mori $\mathrm{H}$. Control of outgrowth and dormancy in axillary buds. Plant Physiol. 2001;127(4):1405-13. 
40. Dun EA, Ferguson BJ, Beveridge CA. Apical dominance and shoot branching. Divergent opinions or divergent mechanisms? Plant Physiology. 2006;142(3):812-9.

41. Ward SP, Leyser O. Shoot branching. Curr Opin Plant Biol. 2004;7(1):73-8

42. Wang Q, Liu N, Yang X, Tu L, Zhang X. Small RNA-mediated responses to low- and high-temperature stresses in cotton. Sci Rep. 2016;6:35558.

43. Zhou L, Liu Y, Liu Z, Kong D, Duan M, Luo L. Genome-wide identification and analysis of drought-responsive microRNAs in Oryza sativa. J Exp Bot. 2010;61(15):4157-68

44. Fujii H, Chiou T-J, Lin S-I, Aung K, Zhu J-K. A miRNA involved in phosphatestarvation response in Arabidopsis. Curr Biol. 2005;15(22):2038-43.

45. Xin $M$, Wang $Y$, Yao $Y$, Xie $C$, Peng $H$, Ni Z, Sun Q. Diverse set of microRNAs are responsive to powdery mildew infection and heat stress in wheat (Triticum aestivum L.). BMC Plant Biol. 2010;10(1):123.

46. Lv D-K, Bai X, Li Y, Ding X-D, Ge Y, Cai H, Ji W, Wu N, Zhu Y-M. Profiling of cold-stress-responsive miRNAs in rice by microarrays. Gene. 2010;459(1-2): 39-47.

47. Nahar K, Hasanuzzaman M, Alam M, Fujita M. Exogenous spermidine alleviates low temperature injury in mung bean (Vigna radiata L.) seedlings by modulating ascorbate-glutathione and glyoxalase pathway. Int J Mol Sci. 2015;16(12):30117-32.

48. Peng T, Zhu X, Duan N, LIU JH. P tr BAM 1, a $\beta$-amylase-coding gene of $P$ oncirus trifoliata, is a CBF regulon member with function in cold tolerance by modulating soluble sugar levels. Plant Cell Environ. 2014;37(12):2754-67.

49. Fernández AP, Strand $\AA$. Retrograde signaling and plant stress: plastid signals initiate cellular stress responses. Curr Opin Plant Biol. 2008;11(5): 509-13.

50. Guy C, Kaplan F, Kopka J, Selbig J, Hincha DK. Metabolomics of temperature stress. Physiol Plant. 2008;132(2):220-35.

51. Yamasaki H, Abdel-Ghany SE, Cohu CM, Kobayashi Y, Shikanai T, Pilon M. Regulation of copper homeostasis by micro-RNA in Arabidopsis. J Biol Chem. 2007;282(22):16369-78.

52. Achard P, Gong F, Cheminant S, Alioua M, Hedden P, Genschik P. The coldinducible CBF1 factor-dependent signaling pathway modulates the accumulation of the growth-repressing DELLA proteins via its effect on gibberellin metabolism. Plant Cell. 2008;20(8):2117-29.

53. Chapman EJ, Estelle M. Mechanism of auxin-regulated gene expression in plants. Annu Rev Genet. 2009;43:265-85.

54. Beveridge CA, Dun EA, Rameau C. Pea has its tendrils in branching discoveries spanning a century from auxin to strigolactones. Plant Physiol. 2009;151(3):985-90.

55. Müller D, Leyser O. Auxin, cytokinin and the control of shoot branching. Ann Bot. 2011;107(7):1203-12.

56. Kebrom TH, Spielmeyer W, Finnegan EJ. Grasses provide new insights into regulation of shoot branching. Trends Plant Sci. 2013;18(1):41-8.

57. Wang $\mathrm{H}$, Wang $\mathrm{H}$. Phytochrome signaling: time to tighten up the loose ends. Mol Plant. 2015;8(4):540-51.

58. Yuan C, Xi L, Kou Y, Zhao Y, Zhao L. Current perspectives on shoot branching regulation. Front Agric Sci Eng. 2015;2(1):38-52.

59. Tanaka M, Takei K, Kojima M, Sakakibara H, Mori H. Auxin controls local cytokinin biosynthesis in the nodal stem in apical dominance. Plant J. 2006; 45(6):1028-36

60. Sekhon RS, Hirsch CN, Childs KL, Breitzman MW, Kell P, Duvick S, Spalding $E P$, Buell CR, de Leon N, Kaeppler SM. Phenotypic and transcriptional analysis of divergently selected maize populations reveals the role of developmental timing in seed size determination. Plant Physiol. 2014;165(2): 658.

61. Le BH, Cheng C, Bui AQ, Wagmaister JA, Henry KF, Pelletier J, Kwong L, Belmonte M, Kirkbride R, Horvath S. Global analysis of gene activity during Arabidopsis seed development and identification of seed-specific transcription factors. Proc Natl Acad Sci. 2010;107(18):8063-70.

62. Agarwal P, Kapoor S, Tyagi AK. Transcription factors regulating the progression of monocot and dicot seed development. Bioessays. 2011;33(3): 189-202.

63. Verdier J, Lalanne D, Pelletier S, Torres-Jerez I, Righetti K, Bandyopadhyay K, Leprince $\mathrm{O}$, Chatelain E, Vu BL, Gouzy J. A regulatory network-based approach dissects late maturation processes related to the acquisition of desiccation tolerance and longevity of Medicago truncatula seeds. Plant Physiol. 2013;163(2):757-74.

64. Li N, Li Y. Signaling pathways of seed size control in plants. Curr Opin Plant Biol. 2016;33:23-32.
65. Becker MG, Hsu S-W, Harada JJ, Belmonte MF: Genomic dissection of the seed. Front Plant Sci 2014, 5(464).

66. Belmonte MF, Kirkbride RC, Stone SL, Pelletier JM, Bui AQ, Yeung EC, Hashimoto M, Fei J, Harada CM, Munoz MD, et al. Comprehensive developmental profiles of gene activity in regions and subregions of the Arabidopsis seed. Proc Natl Acad Sci. 2013;110(5):E435-44.

67. Sreenivasulu N, Wobus U. Seed-development programs: a systems biologybased comparison between dicots and monocots. Annu Rev Plant Biol. 2013;64(1):189-217.

68. Tecza A, Bugner V, Kühl M, Kühl SJ. Pescadillo homologue 1 and Peter Pan function during Xenopus laevis pronephros development. Biol Cell. 2011; 103(10):483-98.

69. Casaretto JA, El-kereamy A, Zeng B, Stiegelmeyer SM, Chen X, Bi Y-M, Rothstein SJ. Expression of OsMYB55 in maize activates stress-responsive genes and enhances heat and drought tolerance. BMC Genomics. 2016; 17(1):312.

70. Williams L, Grigg SP, Xie M, Christensen S, Fletcher JC. Regulation of Arabidopsis shoot apical meristem and lateral organ formation by microRNA miR166g and its AtHD-ZIP target genes. Development. 2005; 132(16):3657-68.

71. Hopper DW, Ghan R, Cramer GR. A rapid dehydration leaf assay reveals stomatal response differences in grapevine genotypes. Horticulture Res. 2014;1:2.

72. Zhang S, Jiang H, Peng S, Korpelainen H, Li C. Sex-related differences in morphological, physiological, and ultrastructural responses of Populus cathayana to chilling. J Exp Bot. 2010;62(2):675-86.

73. Lichtenthaler HK: [34] Chlorophylls and carotenoids: pigments of photosynthetic biomembranes. In: Methods in enzymology. vol. 148: Elsevier; 1987: 350-382.

74. Chen T, Zhang B: Measurements of proline and malondialdehyde content and antioxidant enzyme activities in leaves of drought stressed cotton. Plant \& Cell Physiology 2015

75. Abràmoff MD, Magalhães PJ, Ram SJ. Image processing with ImageJ. Biophoton Int. 2004;11(7):36-42.

76. Ouyang W, Struik PC, Yin X, Yang J. Stomatal conductance, mesophyll conductance, and transpiration efficiency in relation to leaf anatomy in rice and wheat genotypes under drought. J Exp Bot. 2017:68(18):5191-205.

77. Van Dingenen J, De Milde L, Vermeersch M, Maleux K, De Rycke RM, De Bruyne M, Storme V, Gonzalez N, Dhondt S, Inzé D: Chloroplasts are central players in sugar-induced leaf growth. Plant Physiol 2016:pp. 01669.02015.

78. Yuan C, Ahmad S, Cheng T, Wang J, Pan H, Zhao L, Zhang Q. Red to far-red light ratio modulates hormonal and genetic control of axillary bud outgrowth in Chrysanthemum (Dendranthema grandiflorum 'Jinba'). Int J Mol Sci. 2018;19(6):1590

79. Pan X, Welti R, Wang X. Quantitative analysis of major plant hormones in crude plant extracts by high-performance liquid chromatography-mass spectrometry. Nat Protoc. 2010;5(6):986.

80. Zhan J, Thakare D, Ma C, Lloyd A, Nixon NM, Arakaki AM, Burnett WJ, Logan $K O$, Wang $D$, Wang $X$ : RNA sequencing of laser-capture microdissected compartments of the maize kernel identifies regulatory modules associated with endosperm cell differentiation. The Plant Cell 2015:tpc. 114.135657.

81. Maere S, Heymans K, Kuiper M. BiNGO: a Cytoscape plugin to assess overrepresentation of gene ontology categories in biological networks. Bioinformatics. 2005;21(16):3448-9.

82. Zhang B, Horvath S: A general framework for weighted gene co-expression network analysis. Stat Appl Genet Mol Biol 2005, 4(1).

83. Langfelder $\mathrm{P}$, Horvath S. WGCNA: an R package for weighted correlation network analysis. BMC bioinformatics. 2008;9(1):559.

\section{Publisher's Note}

Springer Nature remains neutral with regard to jurisdictional claims in published maps and institutional affiliations. 